\title{
Domain Walls in Random Field Ising Magnets: Wetting
}

\author{
E. Seppala, M. J. Alava, I. Sillanpaa
}

This article was submitted to: International Conference on Magnetism 2003

Roma, Italy

7/21/2003-8/01/2003

\section{June 12, 2003}

U.S. Department of Energy

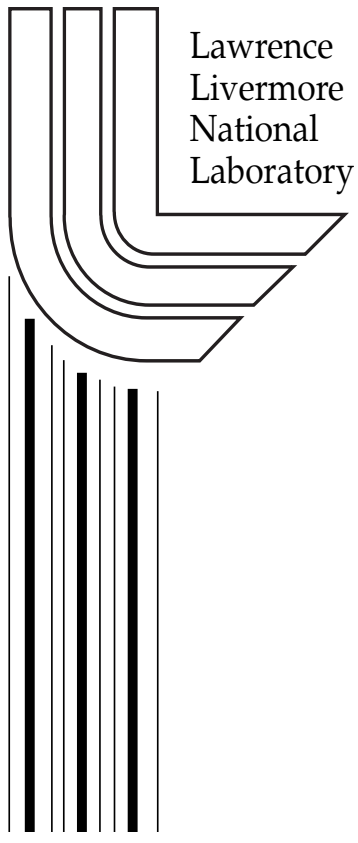




\section{DISCLAIMER}

This document was prepared as an account of work sponsored by an agency of the United States Government. Neither the United States Government nor the University of California nor any of their employees, makes any warranty, express or implied, or assumes any legal liability or responsibility for the accuracy, completeness, or usefulness of any information, apparatus, product, or process disclosed, or represents that its use would not infringe privately owned rights. Reference herein to any specific commercial product, process, or service by trade name, trademark, manufacturer, or otherwise, does not necessarily constitute or imply its endorsement, recommendation, or favoring by the United States Government or the University of California. The views and opinions of authors expressed herein do not necessarily state or reflect those of the United States Government or the University of California, and shall not be used for advertising or product endorsement purposes.

This is a preprint of a paper intended for publication in a journal or proceedings. Since changes may be made before publication, this preprint is made available with the understanding that it will not be cited or reproduced without the permission of the author.

This work was performed under the auspices of the United States Department of Energy by the University of California, Lawrence Livermore National Laboratory under contract No. W-7405-Eng-48.

This report has been reproduced directly from the best available copy.

Available electronically at http://www.doc.gov/bridge

Available for a processing fee to U.S. Department of Energy

And its contractors in paper from

U.S. Department of Energy

Office of Scientific and Technical Information

P.O. Box 62

Oak Ridge, TN 37831-0062

Telephone: (865) 576-8401

Facsimile: (865) 576-5728

E-mail: reports@adonis.osti.gov

Available for the sale to the public from

U.S. Department of Commerce

National Technical Information Service

5285 Port Royal Road

Springfield, VA 22161

Telephone: (800) 553-6847

Facsimile: (703) 605-6900

E-mail: orders@ntis.fedworld.gov

Online ordering: http://www.ntis.gov/ordering.htm

OR

Lawrence Livermore National Laboratory

Technical Information Department's Digital Library

http://www.llnl.gov/tid/Library.html 


\title{
Domain walls in random field Ising magnets: wetting
}

\author{
E. T. Seppälä a M. J. Alava ${ }^{\text {b,c,* I. J. Sillanpää b }}$ \\ ${ }^{a}$ Lawrence Livermore National Laboratory, 7000 East Avenue, L-415, Livermore, CA 94550, U.S.A. \\ ${ }^{\mathrm{b}}$ Helsinki University of Technology, Laboratory of Physics, P.O.Box 1100, FIN-02015 HUT, Finland \\ cSMC-INFM, Dipartimento di Fisica, Università "La Sapienza", P.le A. Moro 200185 Roma, Italy
}

\begin{abstract}
Domain walls in random-field Ising magnets can be investigated in groundstates into which walls are induced by prepared boundary conditions. We outline recent progress, and new results on (domain wall) wetting in random field systems. This is studied in fixed disorder configurations in the presence of an external field, which is varied.
\end{abstract}

Key words: Random field Ising model, Domain walls, Wetting, Quenched randomness PACS: 05.50.+q, 75.50.Lk, 75.60.Ch, 68.45.Gd

The random field Ising model (RFIM) is an example of two competing mechanisms: the local spin couplings favor ferromagnetism (FM) while variations in the random fields favor disorder. In two dimensions (2D) Aizenman and Wehr proved the breakdown of long-range FM order in then groundstates [1], while the three-dimensional case is still studied intensively [2,3]. The nature of the thermodynamic state reflects the domain wall (DW) properties: in the FM state the domains are "stiff", i.e., they have an extensive DW energy.

Such properties can be studied by exact numerical computations by mapping the finding of the RFIM groundstate (GS) into a well-known optimization problem [4]. Domain walls are achieved by imposing suitable opposing boundary conditions. Recent calculations have affirmed in 2D the

\footnotetext{
* Corresponding author: Tel: +358-9-451 3104, Fax: +3589-451 3116

Email address: Mikko.Alava@hut.fi (M. J. Alava).
}

logarithmic correction to the DW energy and the asymptotically paramagnetic (PM) GS character $[5,6]$. The domain walls in the effective FM are not strictly self-affine, and e.g. the roughness has an exponent of $\zeta \simeq 1.2$. Respectively, the energy fluctuations (GS energy distribution width) do not obey the expected exponent relation $\theta=2 \zeta+d-3$ for self-affine DWs or directed polymers with RF disorder $[7,8]$.

The implications of the exponents extend beyond comparisons or tests of analytical theories, to e.g. how the roughness behavior of DW's manifests in the wetting of random field magnets. The meanfield theory for random systems, by Lipowsky and Fisher [9], relates the mean height of the domain wall $\bar{z}$ to the external, binding, field $H$ via $\bar{z} \sim$ $H^{-\psi}$, where $\psi=(2-\zeta) / \zeta$.

Here we present exact numerical simulations with an imposed DW and an external field $H$. Figs. 1(a) and 1(b) illustrate how the wetting takes place with fixed disorder as $H$ is varied (the 

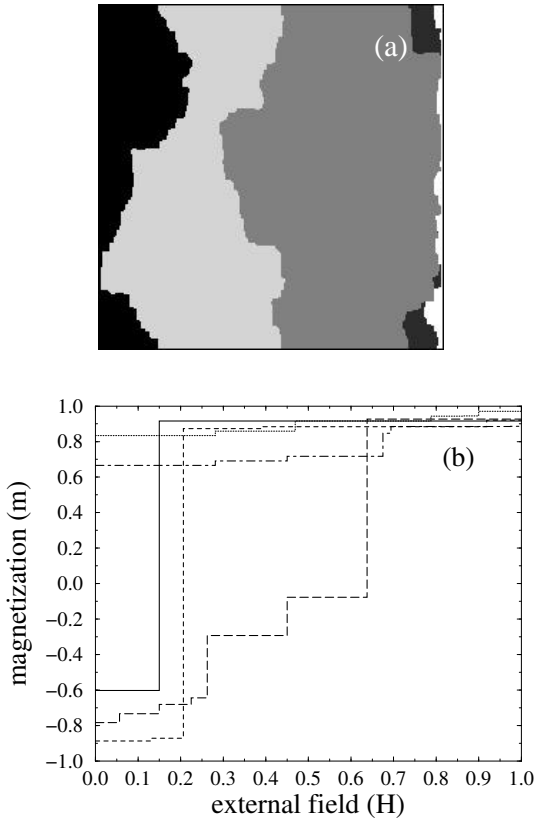

Fig. 1. (a) Examples of successive DW configurations $(\Delta=0.5)$. Different gray colors denote "up" domains at different $H$ values. (b) Magnetization of the full system depending on the mean height $\bar{z}$ vs. the external field $H$ with $\Delta=0.3$ for 5 different random configurations. The system size $L^{2}=240^{2}$ and Gaussian disorder (width $\Delta$ ).

systems are effectively FM). The "dynamics" consists of jumps of various sizes, even macroscopic ones, like in random-bond wetting [10]. This follows from level-crossing. The Hamiltonian has a piecewise continuous derivative w.r.t. $H$ in each disorder configuration.

The effective value of $\zeta$ can be now figured out from $\psi$. If e.g. $\zeta=1 \Rightarrow \psi=1$. For $\zeta=1.2 \Rightarrow \psi=$ 1.5. Fig. 2 shows both the interface and roughness behavior with $\psi=1.5$. Thus the roughness exponent from wetting agrees with earlier direct DW computations.

To summarize, combinatorial optimization is particularly useful for the studies of DW's. The effective $\zeta>1$, manifesting the super-rough behavior of DW's here and the break-down of true scale invariance, hints about the character of the competition between elastic energy and random field fluctuations, for example in the 3D case.

This work was partly performed under the auspices of the U.S. DOE at the UC/LLNL, contract:
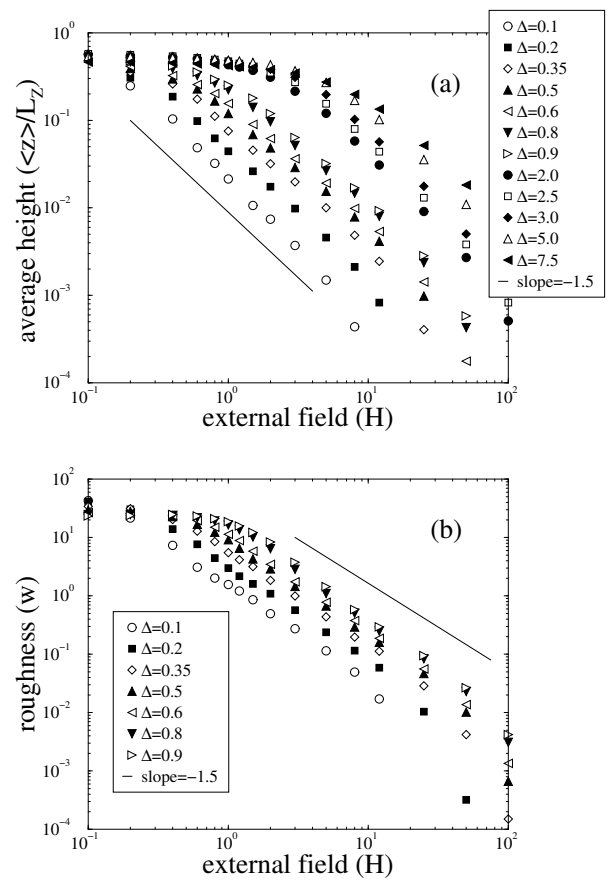

Fig. 2. The scaling of the disorder-averaged interface distance, indicating the value of $\psi$ and the interface roughness, (a): $L^{2}=180^{2}$ (b): $L_{z}=200, L=1000$.

W-7405-Eng-48.

\section{References}

[1] M. Aizenman and J. Wehr, Phys. Rev. Lett. 62, 2503 (1989).

[2] A.A. Middleton and D.S. Fisher, Phys. Rev. B 65 (2002) 134411.

[3] G. Parisi and N. Sourlas, Phys. Rev. Lett. 89, 257204 (2002).

[4] M. Alava et al., in Phase Trans. Crit. Phenom. 18, ed. C. Domb and J. Lebowitz.

[5] K. Binder, Z. Phys. B 50, 343 (1983).

[6] E.T. Seppälä et al. Phys. Rev. E 58 (1998) R5217.

[7] Y.-C. Zhang, J. Phys. A 19, L941 (1986).

[8] E. Frey et al.,Europhys. Lett. 47, 13 (1999).

[9] R. Lipowsky and M. Fisher, Phys. Rev. Lett. 56, 472 (1986).

[10] E.T. Seppälä and M. J. Alava, Phys. Rev. Lett. 84, 3982 (2000). 